\title{
Physical Properties of Activated Slag Concrete Using Phosphogypsum and Waste Lime as an Activator
}

\author{
Seongjin Yoon ${ }^{1}$, Kyoungju Mun ${ }^{2}$ and Wongil Hyung ${ }^{*^{3}}$ \\ ${ }^{1}$ Doctor, Zi-an Industry Co., Ltd., Korea \\ ${ }^{2}$ Doctor, Construction Materials Doctors Group Co., Ltd., Korea \\ ${ }^{3}$ Professor, School of Architecture, Yeungnam University, Korea
}

\begin{abstract}
This study aims to evaluate the physical properties of non-sintering cement (NSC) concrete by adding phosphogypsum (PG) and waste lime (WL) to granulated blast furnace slag (GBFS) as sulfate and alkali activators. The study measured changes in the physical properties of fresh concrete using NSC, and the compressive, flexural and tensile strength of the hardened concrete for 360 days. In the results of the experiment, concrete using NSC was superior to that using Ordinary Portland Cement (OPC) or blast-furnace slag cement (BSC) in terms of fluidity and hydration heat characteristics. In addition, the early strength of concrete using NSC was relatively low at around $85 \%$ of the strength of concrete using OPC on day 3 , but this was reversed from day 7 and the difference between OPC and BSC grew steadily larger over time until day 360. The strength of concrete using NSC develops continuously because the GBFS component eluting as GBFS is activated by PG and WL, and due to their reaction, ettringite, C-S-H gel, etc. are generated steadily for a long time, and there is no transition zone in the interface between the aggregate and paste because $\mathrm{Ca}$ $(\mathrm{OH})_{2}$ is hardly generated from the hydration process, and as a result, interfacial adhesion is reinforced with aging.
\end{abstract}

Keywords: granulated blast-furnace slag; phosphogypsum; waste lime; waste management; hydration

\section{Introduction}

Greenhouse gas reduction will be highlighted as the most pending question in the cement industry in future because the production of Portland cement not only consumes limestone, clay, coal, and electricity, but also releases waste gases such as $\mathrm{CO}_{2}, \mathrm{SO}_{3}$, and $\mathrm{NO}_{\mathrm{x}}$, which can contribute to the greenhouse effect and acid rain. GBFS is a byproduct generated from the iron manufacturing process. It does not become hydrated upon contact with water, but tends to be hydrated and hardened when adding activators, such as alkali or sulfate ${ }^{1), 2)}$. In Korea, 30 million tons of PG and 3 million tons of WL have been accumulating as wastes $^{3)}$, and their disposal has become a serious social issue $^{4)}$.

This study aims to evaluate the physical properties of non-sintering cement (NSC) concrete by adding phosphogypsum (PG) and waste lime (WL) to

*Contact Author: Wongil Hyung, Professor,

School of Architecture, Yeungnam University,

Dae-dong, Gyeongsan, 712-749, Korea

Tel: +82-53-810-2597 Fax: +82-53-810-4625

E-mail: beda@yu.ac.kr

(Received April 7, 2014 ; accepted November 14, 2014) granulated blast furnace slag (GBFS) as sulfate and alkali activators.

In order to examine changes in the physical properties of fresh concrete using NSC, authors measured slump, air content, bleeding, and hydration heat. In addition, the strength characteristics of hardened concrete were examined by measuring the compressive, flexural, and tensile strength from 3 to 360-days and analyzing the internal microscopic structure. This study also investigates the basic physical properties and quality of concrete using NSC, and evaluates the possibility of reusing it as a construction material.

\section{Experiment}

\subsection{Raw Materials for Binder Systems Samples}

The blast furnace slag used was obtained from a K steel plant in Korea. The PG used for the sulfate activator was obtained from a phosphoric acid factory (N-Chemical) as a filter cake. The waste lime used for the alkali activator was obtained from a sodium carbonate $\left(\mathrm{Na}_{2} \mathrm{CO}_{3}\right)$ factory (D-Chemical) as a filter cake. Also, a small quantity of commercial slacked lime (SL) was applied as an alkali activator. BFS was ground in a laboratory ball mill and the material passed through a 30-micron sieve was used in the preparation of cement 
Table 1. Chemical Composition and Physical Properties of Raw Materials

\begin{tabular}{c|c|c|c|c|c|c|c|c|c|c|c|c|c|c}
\hline Inpe & \multicolumn{10}{c|}{ Oxide composition (\%) } & \multirow{2}{*}{$\begin{array}{c}\text { Blaine } \\
\left(\mathrm{g} / \mathrm{cm}^{2}\right)\end{array}$} & $\begin{array}{c}\text { Specific } \\
\text { gravity }\end{array}$ \\
\hline & $\mathrm{SiO}_{2}$ & $\mathrm{Al}_{2} \mathrm{O}_{3}$ & $\mathrm{CaO}$ & $\mathrm{Fe}_{2} \mathrm{O}_{3}$ & $\mathrm{MgO}$ & $\mathrm{Na}_{2} \mathrm{O}$ & $\mathrm{K}_{2} \mathrm{O}$ & $\mathrm{P}_{2} \mathrm{O}_{5}$ & $\mathrm{TiO}_{2}$ & $\mathrm{SO}_{3}$ & $\mathrm{LOI}$ & & \\
\hline GBFS & 34.76 & 14.50 & 41.71 & 0.48 & 6.87 & 0.14 & 0.44 & 0.03 & 0.62 & 0.13 & 0.23 & 4,600 & 2.91 \\
\hline $\mathrm{APG}$ & 1.34 & 0.12 & 40.97 & 0.04 & - & 0.06 & - & 0.64 & 0.05 & 54.93 & 0.81 & 4,300 & 2.88 \\
\hline $\mathrm{DPG}$ & 1.08 & 0.07 & 32.28 & 0.21 & 0.05 & - & - & 0.58 & 0.04 & 43.29 & 22.37 & 4,100 & 2.36 \\
\hline $\mathrm{SL}$ & - & 0.19 & 65.88 & 0.12 & 1.03 & - & - & - & 0.03 & 1.13 & 31.51 & 5,400 & 2.27 \\
\hline $\mathrm{WL}$ & 4.88 & 1.62 & 42.12 & 1.35 & 6.89 & 0.11 & 1.89 & 0.02 & 0.02 & 3.12 & 33.17 & 4,100 & 2.22 \\
\hline $\mathrm{OPC}$ & 20.88 & 5.39 & 64.73 & 2.38 & 1.51 & 0.27 & 0.22 & - & 1.33 & 1.65 & 2.04 & 3,300 & 3.15 \\
\hline
\end{tabular}

Table 2. Mix Proportions of Concrete Using Various NSCs

\begin{tabular}{|c|c|c|c|c|c|c|c|c|c|c|c|c|c|c|}
\hline \multirow[t]{2}{*}{ Type } & \multicolumn{6}{|c|}{ Mix proportions of NSC (wt\%) } & \multirow{2}{*}{$\begin{array}{l}\text { Gmax } \\
(\mathrm{mm})\end{array}$} & \multirow{2}{*}{$\begin{array}{l}\mathrm{W} / \mathrm{C} \\
(\%)\end{array}$} & \multirow{2}{*}{$\begin{array}{l}\text { S/a } \\
(\%)\end{array}$} & \multirow{2}{*}{$\begin{array}{c}\mathrm{W} \\
\left(\mathrm{kg} / \mathrm{m}^{3}\right)\end{array}$} & \multicolumn{3}{|c|}{$\begin{array}{l}\text { Mixing proportion } \\
\qquad\left(\mathrm{kg} / \mathrm{m}^{3}\right)\end{array}$} & \multirow{2}{*}{$\begin{array}{c}\text { Air entraining and } \\
\text { water reducing } \\
\text { agent }\end{array}$} \\
\hline & $\mathrm{OPC}$ & GBFS & $\mathrm{AG}$ & DG & SL & WL & & & & & $\mathrm{C}$ & $\mathrm{S}$ & G & \\
\hline $\mathrm{OPC}$ & 100 & - & - & - & - & - & \multirow{7}{*}{20} & \multirow{7}{*}{45} & \multirow{7}{*}{41} & \multirow{7}{*}{179} & \multirow{7}{*}{397} & \multirow{7}{*}{736} & \multirow{7}{*}{1060} & \multirow{7}{*}{$\mathrm{C} \times 0.5 \%$} \\
\hline $\mathrm{BSC}$ & 50 & 50 & - & - & - & - & & & & & & & & \\
\hline NSC1 & - & 87 & 12 & - & 1 & - & & & & & & & & \\
\hline NSC2 & - & 87 & 6 & 6 & 1 & - & & & & & & & & \\
\hline NSC3 & - & 82 & - & 17 & 1 & - & & & & & & & & \\
\hline NSC4 & - & 85 & 11 & - & - & 4 & & & & & & & & \\
\hline NSC5 & - & 81 & 11 & - & - & 8 & & & & & & & & \\
\hline
\end{tabular}

samples. The blain's surface areas of GBFS were 4,600 $\mathrm{cm}^{2} / \mathrm{g}$. The glass content of the GBFS, was $99.8 \%$ as determined by the optical microscopic method. PG was prepared by washing with $0.5 \%$ milk of lime at $20^{\circ} \mathrm{C}$ for $5 \mathrm{~min}$. The $\mathrm{PG} / \mathrm{milk}$ of lime ratio was $14 \%$ by weight. After neutralization treatment, the PG was dried at $80^{\circ} \mathrm{C}$ in order to obtain dehydrate gypsum $\left(\mathrm{CaSO}_{4} \cdot 2 \mathrm{H}_{2} \mathrm{O}, \mathrm{DPG}\right)$ and was calcined at $450^{\circ} \mathrm{C}$ in order to obtain anhydrite (II-CaSO 4, APG). Then, the DPG and APG were refined by refiner machine ${ }^{5), 6)}$. Waste lime was dried at $90^{\circ} \mathrm{C}$ for 1-day and refined by a refiner machine. OPC and blast-furnace slag cement (BSC) were applied in order to compare their physical properties with that of NSC. Their chemical and physical properties are shown in Table 1. Crushed stone $20 \mathrm{~mm}$ (specific gravity $=2.60 \mathrm{~g} / \mathrm{cm}^{3}$, F.M. $=6.68$ ) was used as coarse aggregate, and river sand was used as fine aggregate for the physical concrete test. AE waterreducing admixture of naphthalene type was used to secure the fluidity and air content.

\subsection{Mixture Proportion and Experimental Method}

The NSC mixtures were prepared by mixing different proportions of GBFS, PG, WL and SL. Table 2. shows the mix proportion of concrete using various NSCs. In an experiment with fresh concrete, slump, air content, and bleeding tests were performed according to KS F 2402, 2421 and 2414, respectively. In order to measure hydration reaction heat according to the age of concrete by cement type, authors prepared a $64 \ell$ $(40 \times 40 \times 50 \mathrm{~cm})$ mold insulated with insulation material, placed concrete just after mixing, and measured the change of temperature inside the concrete by setting a thermocouple at the core of the concrete and using a data logger (TDS-602). In order to compare the strength characteristics of concrete, authors prepared specimens according to $\mathrm{KS} F$ 2405, placed them in $\varnothing 10 \times 20 \mathrm{~cm}$ and $15 \times 1,5 \times 55 \mathrm{~cm}$ molds, cured them in a standard curing room $\left(20^{\circ} \mathrm{C}, 50 \% \mathrm{RH}\right)$ for a day, cured them in water at $20 \pm 2^{\circ} \mathrm{C}$, and then measured the compressive, flexural and tensile strength at the age of 3 , 7, 28, 90, and 360-days.

\section{Results and Discussion}

\subsection{Slump and Air Content of Fresh Concrete}

Fig.1. shows the results of experiments on slump and air content according to cement type. In terms of fluidity, NSC concrete was generally superior to OPC or BSC concrete except NSC 4 and 5, which used WL. This was due to the fact that the surface of GBFS is of a smooth wave form, and the interface lubrication effect of acidic film formed on the surface increases lubrication among the particles of fresh concrete ${ }^{6), 7), 8)}$.

As to the fluidity of concrete according to the type of activator, in the case of PG used as a sulfate activator, fluidity was not affected much by whether anhydrite or hydrate gypsum were used, but fluidity showed the tendency of decreasing with the increase in the content of WL and the decrease in the content of GBFS. In the results of an experiment on air content, NSC showed the tendency of decreasing compared to OPC and BSC and this was due to the fact that the GBFS used in the experiment has a higher fineness $\left(4,600 \mathrm{~cm}^{2} / \mathrm{g}\right)$ than OPC and its content is $81 \sim 87 \%$, almost 2 times higher than that of BSC, and thus the inter-particle filling effect is enhanced by the fineness. As to the air content of NSC according to the activator type, the air content decreased markedly in NSC 4 and 5 containing WL as an alkali activator. 
Fig.2. shows the slump loss of concrete over time. Slump loss was significantly less in concrete using NSC than in OPC, and also less than in BSC. This was due to the content of GBFS, whose surface adsorption of dispersant is lower than OPC, which was high. That is, the setting time was lengthened by admixture and cement not being adsorbed into the surface of the dispersant and by redundant water not being involved in the early hydration reaction. A low rate of slump decrease means that the security of workability lasts for a longer time.

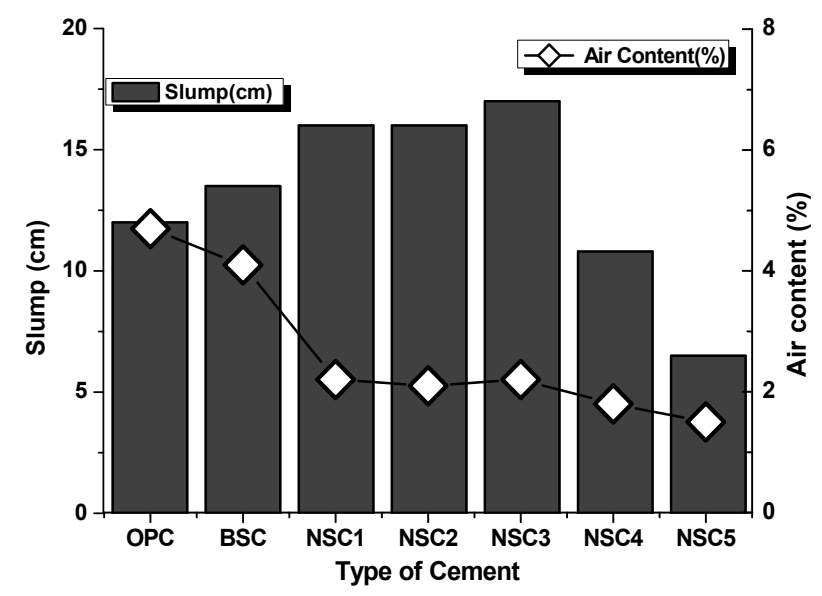

Fig.1. Slump and Air Content of Fresh Concretes with Various Cement Types



Fig.2. Slump Loss of Concrete Over Time According to Cement Type

\subsection{Bleeding of Fresh Concrete}

Fig.3. shows the bleeding capacity of fresh concrete over time according to cement type. In general, bleeding capacity decreases with the increase in fineness, but in authors experiment, the bleeding capacity of BSC and NSC concrete was somewhat higher than that of OPC. This is probably because when the content of GBFS is high the fluidity of concrete increases and there exists some redundant water and the low activity of GBFS delays early hydration reaction to some degree ${ }^{3)}$. In the case of PG as well, bleeding capacity did not decrease notably because the overall adsorption of water was not much, and in the case of NSC3 added in the form of DPG, bleeding capacity was much higher than that of NSC1 that used only APG. In the case of NSC 4 and 5 that used WL, however, bleeding capacity decreased considerably as WL adsorbed water.

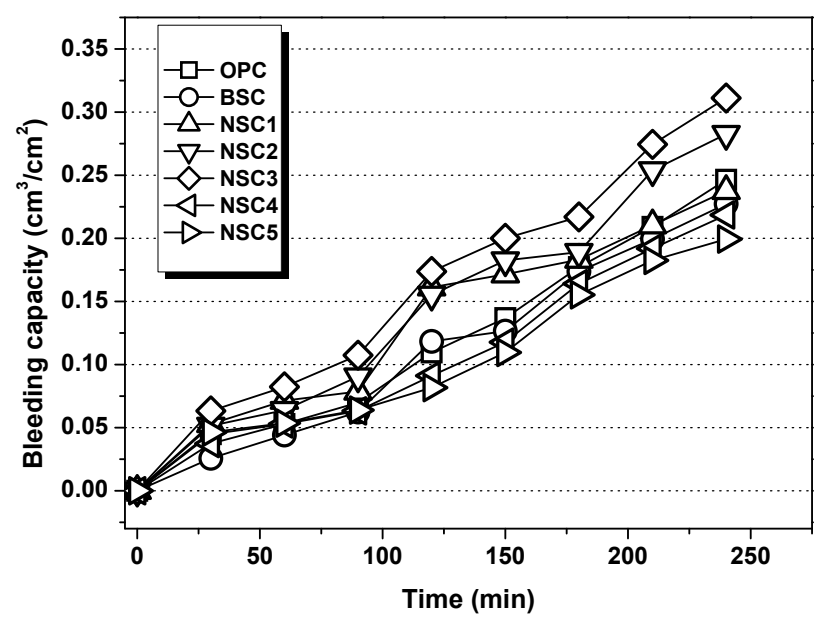

Fig.3. Bleeding Capacity of Fresh Concrete Over Time According to Cement Type

\subsection{Hydration Temperature During Setting and Hardening}

Fig.4. shows the temperature of specimens in a simple adiabatic temperature test for OPC, BSC and NSC1. Peak temperature was high in the order of OPC $>$ BSC $>$ NSC1, and the time to reach the peak temperature was long in the reverse order. Peak temperature was $60^{\circ} \mathrm{C}$ in concrete using $\mathrm{OPC}, 52.7^{\circ} \mathrm{C}$ in $\mathrm{BSC}$, and $48.9^{\circ} \mathrm{C}$ in $\mathrm{NSC} 1$. The time to reach the peak temperature in the core was 14 hours in OPC, 22 hours in BSC, and 27 hours in NSC1. That is, peak temperature decreased and the time to reach the peak temperature increased with the decrease in the OPC content. The rise of concrete temperature by the hydration heat of cement in the process of concrete hardening affects the properties of the concrete including strength development. Particularly in the case of high-strength concrete with a large unit volume of cement and mass concrete with difficulty in the emission of internal temperature, it is not easy to have cracks or the lowering of strength due to temperature stress resulting from the temperature difference between the inside and outside of the concrete. Thus, it is considered very effective if NSC is used as a substitute for OPC and BSC in order to lower hydration heat because NSC does not contain clinker in OPC.

Fig. 5. compared hydration heat characteristic according to the mixture of NSC cement. Hydration heat was highest in NSC1 using APG, and decreased by $3.1^{\circ} \mathrm{C}$ in NSC2 using some DPG together with APG compared to $\mathrm{NSC} 1$ and decreased by $3.9^{\circ} \mathrm{C}$ in $\mathrm{NSC} 3$ using DPG only. This was due to the fact that the 
hydration heat of APG is higher than that of DPG. The time to reach the peak temperature was around 3 hours shorter in NSC2 than in NSC1, but around 7 hours longer in NSC3 than in NSC1. In the case of NSC4 and NSC5 using WL, the temperature was higher than that of NSC1 for the first 16 hours of hydration and then went down gradually, and their peak temperature was lowest while their time to reach the peak temperature was long. This was due to the fact that the elution rate and activation of WL are very slow. These results show that the hydration heat of NSC is very low and the use of DPG or WL as an activator is quite effective in reducing hydration heat further.

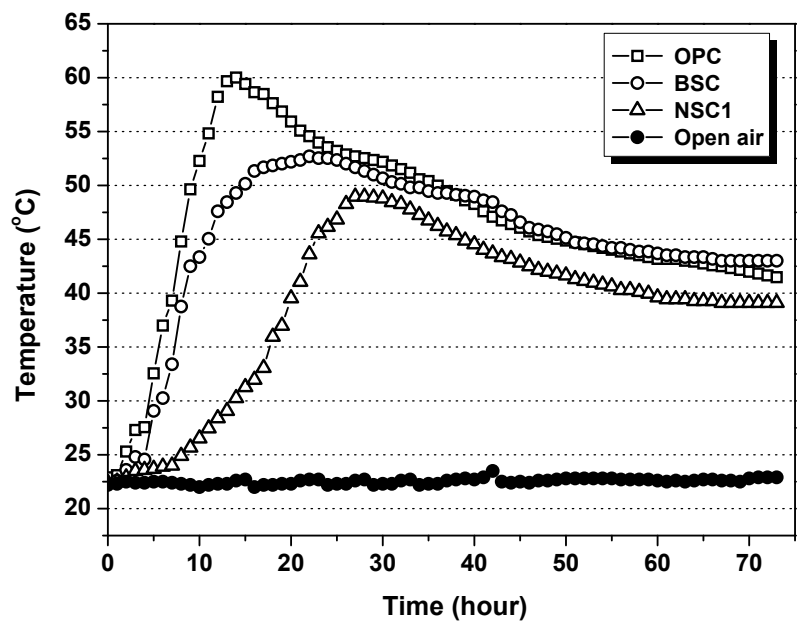

Fig.4. Temperature of Specimens in a Simple Adiabatic Temperature Test for OPC, BSC and NSC1

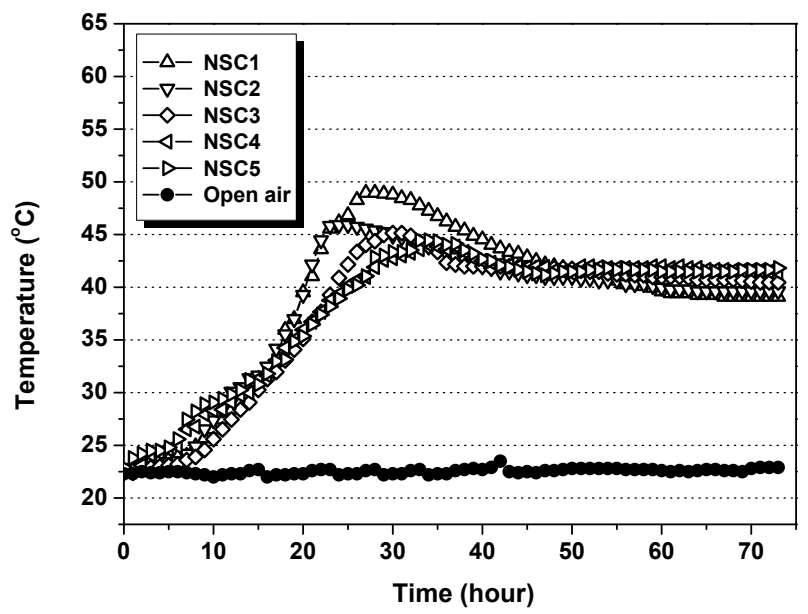

Fig.5. Hydration Temperature Compared Hydration Heat Characteristic According to the Mixture of NSC Cement

\subsection{Strength}

Fig.6. shows the results of an experiment on concrete strength according to cement type. In general, compressive, flexural, and tensile strength show similar tendencies according to age. NSC concrete was less strong than OPC at the age of 3-days but it was reversed from day 7 and the difference grew larger with aging as the strength of NSC concrete increased steadily. Particularly from day 28, concrete using OPC showed a slowdown in the increase of strength but NSC concrete showed the tendency of steady increase of strength in an almost linear form until day 360 . Furthermore, NSC1 had a higher strength than BSC at the early age. The strength of NSC2, the concrete of cement mixture in which $50 \%$ of APG was replaced with DPG, was lower than that of concrete using only APG on day 3 , but was almost equal at the age of 7 360-days. The strength of NSC3, the concrete of cement mixture using DPG as an activator instead of APG, was around $75 \%$ of the mixture of NSC1 on day 3 , but around $80 \%$ on day 7 and almost equal from day 28. Because the elution of APG, a soluble substance, is around 2 times larger than DPG, there are more opportunities to contact acidic film on the surface of a GBFS particle, and because APG has higher hydration heat emitted during elution than DPG, the use of APG increases early strength but, over time, its effect weakens gradually and in the end it becomes similar to that with the use of $\mathrm{DPG}^{6), 7)}$.

In the case of NSC4 and NSC5 containing WL, strength during the first three days is quite low at around $70 \sim 75 \%$ of that of NSC1, but their compressive strength on day 7 and day 28 is almost identical with that of NSC2. In particular, NSC5 shows the highest strength at the age of 90 days and afterward. This was due to the fact that the alkali activation of WL is weaker than that of SL but it continuously maintains an atmosphere of over pH12 and, after all, destroys the acidic film of GBFS. It is believed that there is high improvement in strength at a long age because hydrate is generated from hydration reaction between modified ion and PG inside GBFS, and substances other than calcium hydroxide inside WL such as calcium carbonate and other inorganic materials behave stably while playing the role of filler without hindering

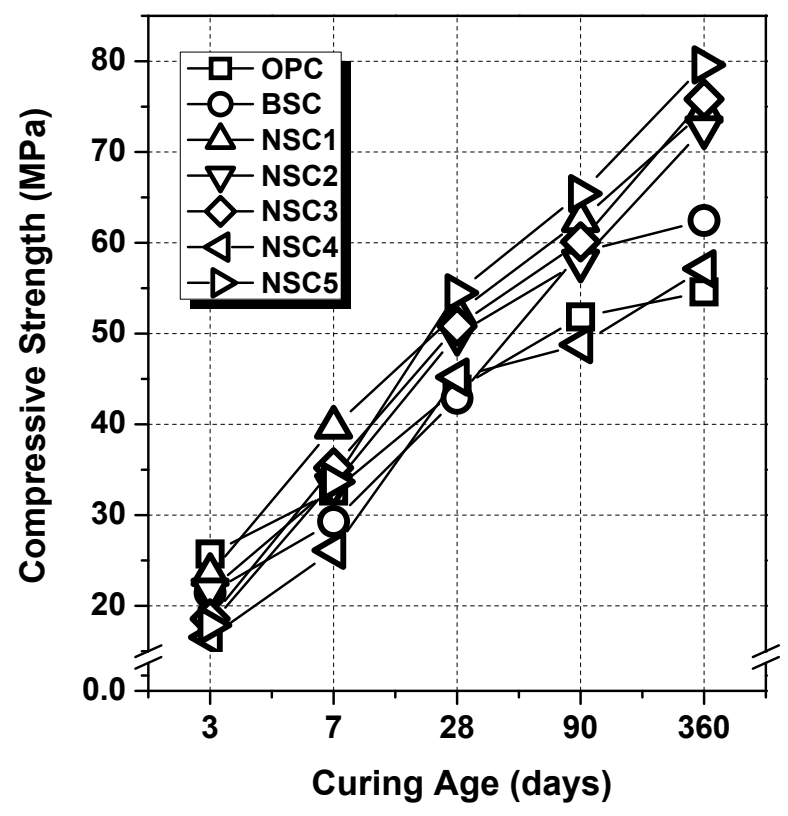

a) Compressive strength 


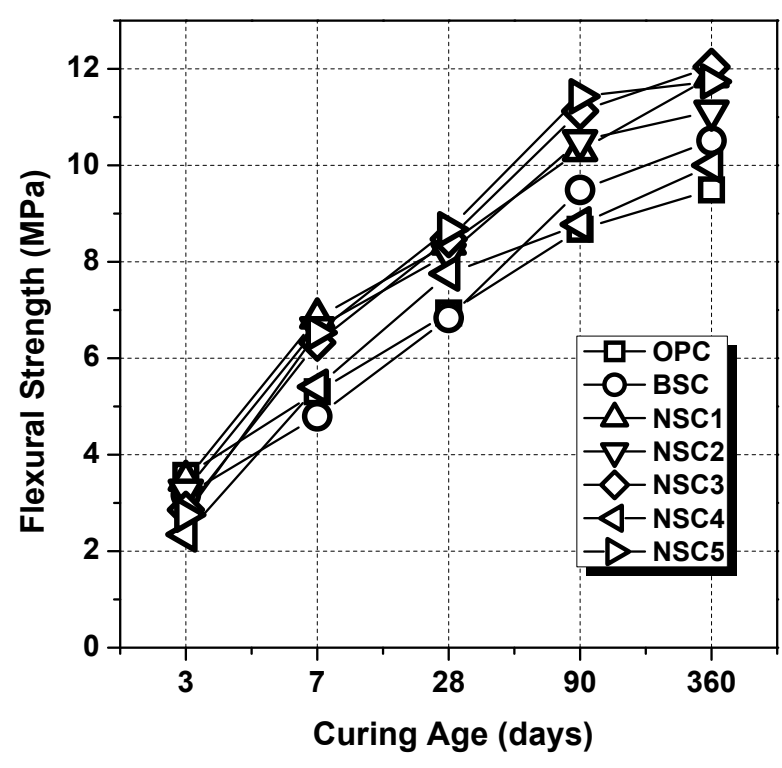

(b) Flexural strength

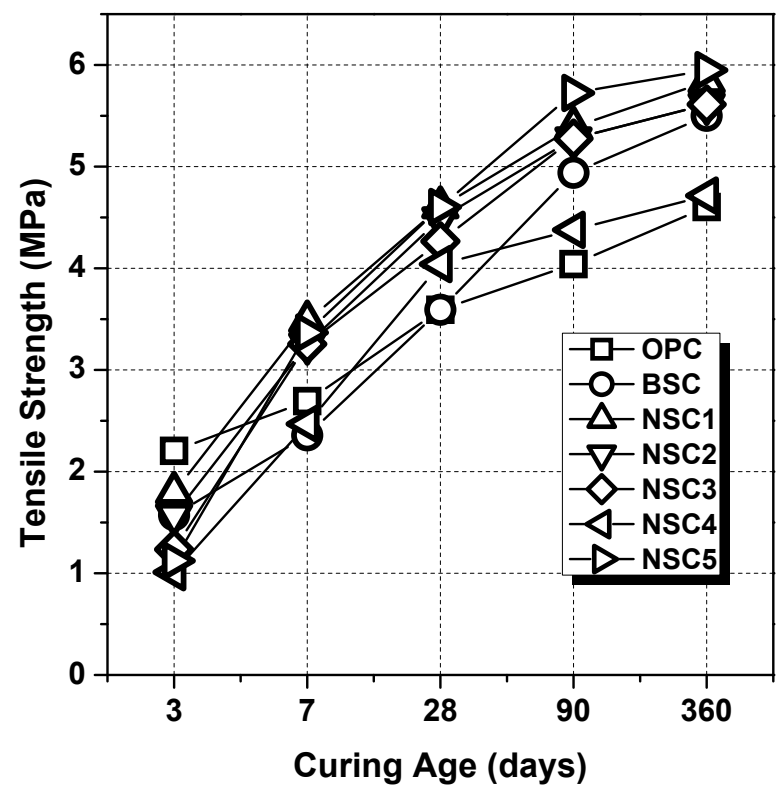

(c) Tensile strength

Fig.6. Strength of Concretes with Various Cement Types

the hydration reaction. Accordingly, it is considered possible to reduce the input of GBFS and manufacture superior cement of high economic efficiency using WL, an industrial waste, as an alkali activator along with DPG in manufacturing secondary products of concrete without considering early strength. Compared to OPC and BSC, NSC can develop higher strength at a long age because by the activation effect of $\mathrm{PG}$ and WL, the elution of GBFS components and their reaction generates ettringite, $\mathrm{C}-\mathrm{S}-\mathrm{H}$ gel, etc. steadily even at a long age ${ }^{8), 9), 10), 11)}$. As a result, the maximum compressive strength of a 1-year-old specimen of NSC concrete is around 1.5 times higher than that of OPC and around 1.25 times higher than that of BSC.

\subsection{Distribution of Transition Zone Inside Concrete}

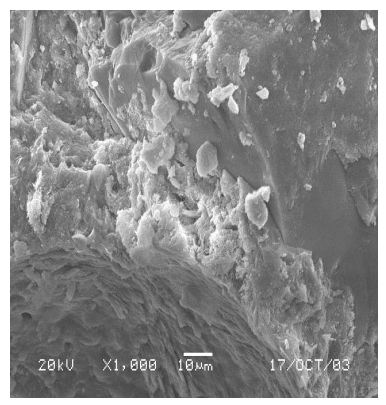

(a) OPC

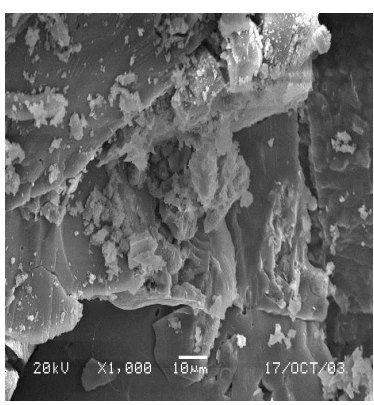

(b) BSC

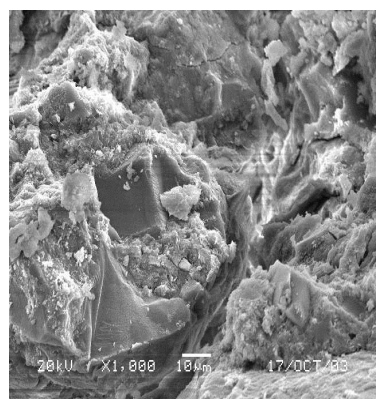

(c) NSC

Fig.7. SEM Analysis of Aggregate Interface Inside Concrete Using OPC, BSC and NSC at the Age of 90 Days

Fig.7. shows the result of SEM analysis of aggregate interface inside concrete using OPC, BSC and NSC at the age of 90 days. The discontinuous area existing between aggregate and paste is called a transition zone, and is formed mainly by $\mathrm{Ca}(\mathrm{OH})_{2}$ crystal (within $75 \mu \mathrm{m})$. In the case of OPC, $\mathrm{Ca}(\mathrm{OH})_{2}$ eluted on the surface of aggregate is around $25 \mu \mathrm{m}$ thick, and as the transition zone does not have an adhesive force, if it receives pressure, cracks occur and spread by the concentration of stress. Therefore, the quantitative change in the transition zone has a significant effect on compressive strength. In the case of $\mathrm{BSC}, \mathrm{Ca}(\mathrm{OH})_{2}$ generated from OPC is consumed mostly through hydration reaction with GBFS, and therefore, the width and volume of the transition zone decreases considerably compared to that in OPC. Furthermore, NSC cement generates little $\mathrm{Ca}(\mathrm{OH})_{2}$ in the hydration process, so it does not have a transition zone in the interface between aggregate and paste and, as a result, the adhesive force and compressive strength increase over time ${ }^{12), 13), 14)}$.

\subsection{Pore Size Distribution and Pore Volume}

Figs.8. and 9. show, respectively, the ratios of flexural and tensile strength to compressive strength in NSC concrete. Different from those in OPC and BSC, the ratios of flexural and tensile strength to compressive strength in NSC concrete vary slightly according to age. The flexural strength of OPC and BSC concrete is around $15 \sim 17 \%$ of compressive strength, and increases gradually or remains almost constant over time. In contrast, the flexural strength of NSC concrete is 
around 15 20\%, slightly higher than that of OPC and $\mathrm{BSC}$ and, in particular, flexural strength at the age of 7 days is around $18 \sim 20 \%$ of compressive strength, higher than that at other ages. The tensile strength of OPC and $\mathrm{BSC}$ concrete is around 7.5 9\% of compressive strength, and is almost constant regardless of age. The tensile strength of NSC is $7.5 \sim 10 \%$ of compressive strength, slightly higher than that of OPC and BSC. Its tensile strength at the age of 7 -days is $9 \sim 10 \%$ of compressive strength, higher than that at other ages. The reason why the ratios of flexural and compressive strength to compressive strength are higher at the age

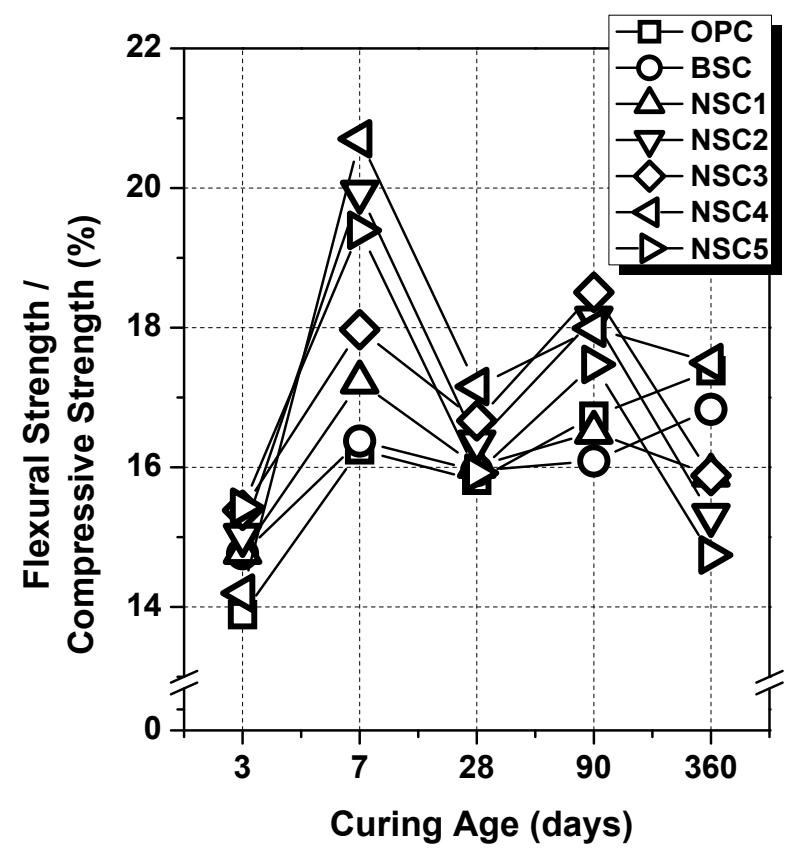

Fig.8. Flexural Strength/Compressive Strength Ratio of Concretes with Various Cement Types

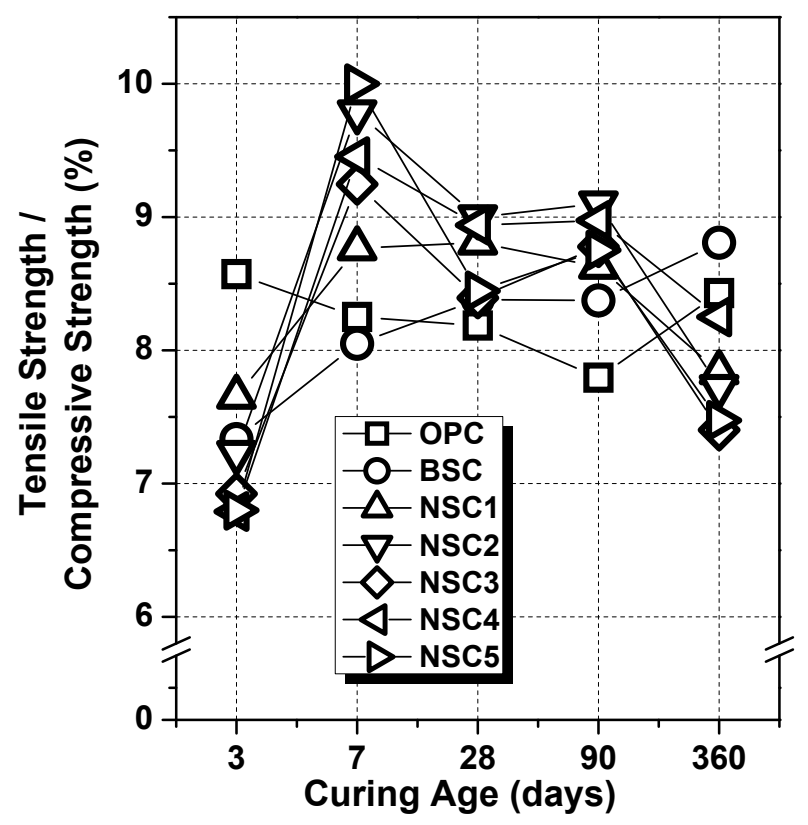

Fig.9. Tensile Strength/Compressive Strength Ratio of Concretes with Various Cement Types of 7-days than at other ages in NSC concrete may be that the production of ettringite, a needle-like crystal substance, reaches its peak at the age of 7-days and the substance plays the role of a fine short staple and form network structure inside the hardened concrete.

\section{Conclusion}

As a measure to save resources and energy and reuse industrial byproducts in the cement industry, this study evaluated the basic properties of concrete using NSC. The results are as follows:

1. As to the characteristics of fresh concrete, NSC was superior to OPC or BSC in fluidity and hydration heat, but not in air content and bleeding capacity.

2. Though the strength of concrete using NSC is low during the initial 3-days, it shows equal or higher strength development compared to OPC or BSC after 7-days and onwards.

3. Owing to continuous reactions of GBFS, PG and WL during the long-term strength development of NSC concrete, ettringite and $\mathrm{C}-\mathrm{S}-\mathrm{H}$ gel are generated even in long age, and little $\mathrm{Ca}(\mathrm{OH})_{2}$ is generated during concrete hydration. This might be because as a result, transition zones are not created in the interfaces of aggregate and paste, causing excellent adhensivity to interfaces.

4. Should strength at the early stage not be considered as an important factor, use of waste gypsum and waste lime landfill with simple preconditioning process reduces the volume of furnace slag powder to be used and so enables manufacturers to produce NSC with economic merits.

\section{Acknowledgment}

This work was supported by the National Research Foundation of Korea Grant funded by the Korean Government (MSIP) (2014, Joint Research Corporations Support Program).

\section{References}

1) K. J. Mun, Properties of non-sintered cement and concrete recycled with industrial waste, Ph.D. Thesis, Chonbuk National University, 2002, pp.63-77.

2) Emin Erdem and Halis Olmez, The Mechanical Properties of Supersulphated Cement Containing Phosphogypsum, Cem. Concr. Res. 23 (1) (2000), pp.115-121.

3) K.J. Mun, W.K. Hyoung, C.W. Lee, S.Y. So and Y.S. Soh, Basic properties of non-sintering cement using phosphogypsum and waste lime as activator, Constr. Build. Mater. 21 (6) (2007), pp.1342-1350.

4) A. Carbonell-Barrachina, R. D. DeLaune and A. Jugsujinda, Phosphogypsum chemistry under highly anoxic conditions, Waste Manage. 22 (6) (2002), pp.657-665.

5) J. Bijen and E. Niël, Supersulphated cement from blast furnace slag and chemical gypsum available in the Netherlands and neighbouring countries, Cem. Concr. Res. 11 (3) (1981), pp.307-322.

6) Emin Erdem and Halis Olmez, The Mechanical Properties of Supersulphated Cement Containing Phosphogypsum, Cem. Concr. Res. 23 (1) (1993), pp.115-121.

7) A. Gruskovnjak, B. Lothenbach, F. Winnefeld, R. Figi, S.-C. Ko, M. Adler and U. Mäder, Hydration mechanisms of super sulphated slag cement, Cem. Concr. Res. 38 (7) (2008), pp.983-922. 
8) Peiyu Yan and Wenyan Yang, The cementitious binder derived with fluorogypsum and low quality of fly ash, Cem. Concr. Res. 30 (2) (2000), pp.275-280.

9) H.G. Midgley and K. Pettifer, The microstructure of hydrated super sulphated cement, Cem. Concr. Res. 1 (1) (1971), pp.101-104.

10) T. K. Dan and M. K. Chatterjee, Activation of an Indian Blast Furnace Slag by Lime and Lime-Gypsum Mixed Activator in Solution Phase, Indian J. Technol. 23 (9) (1985), pp.337-344.

11) J. Bijen and E. Niël, Supersulphated Cement: Improved Properties, Silic. Ind. 47 (2) (1982), pp.45-53.

12) A. S. Taha, H. El-Didamony, S. A. Abo-El-Enefin, H. A. Amer, Physico-Chemical Properties of Supersulphated Cement Pastes, ZKG. Int. Ed. B. 34(6) (1981) pp.315-317.

13) M. Singh and M. Garg, Phosphogypsum-fly ash cementitous binder-its hydration and strength development, Cem. Concr. Res. 25 (1995) (4), pp.752-758.

14) J.I. Escalante, A. Fernández, P.E. Fraire and G. Mendoza, Hydration products and reactivity of blast furnace slag activated by various alkalis, J. Am. Ceram. Soc. 86 (12) (2003), pp.2148-2153. 